\title{
Form, Content, and Space: Methodological Challenges in the Study of Medieval and Early Modern European Graffiti
}

Mia Gaia Trentin ${ }^{1}$

How to cite: Trentin, M G. Form, Content, and Space: Methodological Challenges in the Study of Medieval and Early Modern European Graffiti. Papers from the Institute of Archaeology, 2021, 30(1): pp. 1-25. DOI: https://doi.org/10.14324/111.444.2041$\underline{9015.1283}$

Published: 15/11/2021

\section{Peer Review:}

This article has been peer reviewed through the journal's standard double-blind review.

\section{Copyright:}

(C) 2021, The Author(s). This is an Open Access article distributed under the terms of the Creative Commons Attribution License (CC-BY) $4.0 \mathrm{https}: / /$ creativecommons.org/licenses/by/4.0/, which permits unrestricted use, distribution and reproduction in any medium, provided the original author and source are credited • DOI: https://doi.org/10.14324/111.444.2041-9015.1283

\section{Open Access:}

Papers from the Institute of Archaeology is a peer-reviewed open access journal. 


\title{
CONFERENCE PROCEEDINGS: TIMELESS SPACES 2019*
}

\section{Form, Content, and Space: Methodological Challenges in the Study of Medieval and Early Modern European Graffiti}

\author{
Mia Gaia Trentin
}

\begin{abstract}
Scholars of various disciplines have focused their attention on European Medieval and Early Modern graffiti during the last decade, thus confirming and reinforcing the value of this peculiar written evidence. Their contributions demonstrate that graffiti can offer valuable information to different fields of study (e.g. shipbuilding, palaeography, history, social culture, and visual culture) through a glimpse into past daily life. Due to their nature, graffiti present a completely free graphic expression, which may appear in either textual or pictorial forms, or both. This characteristic makes their study rather challenging due to the two different mechanisms of communication they employ. In the case of textual graffiti, the content is transmitted through linguistic codification, while pictorial graffiti require a decoding process that is more complex and articulated. The first challenge, though, is to find a way to record and compare both evidence on the same graphic and verbal levels. Furthermore, as for any other epigraphic evidence, the graffiti analysis must take into account the writing surfaces and the context, two elements that are fundamental for the final interpretation of this source. This paper will address these methodological issues concerning the preliminary phase of graffiti documentation and classification/cataloguing. The starting point has been the recent debate and application of FAIR data principles in the field of Humanities, which aim to create quality data, easily exchanged in a digital environment, fostering knowledge in the field. Since this approach has not yet been applied to graffiti studies, the paper aims to stimulate a dialogue on innovative and objective methodological approaches within the researchers' community.
\end{abstract}

\section{Methodological Context}

In recent years, the definition of FAIR principles in the field of Sciences has fostered the creation of Findable, Accessible, Interoperable, and Reproducible data (FAIR;

"Timeless Spaces: Between Art, Politics, and Vandalism, a Seminar on Ancient and Modern Graffiti was a conference held at the Institute of Archaeology, University College London on the $16^{\text {th }}$ of March 2019, organised by Rosamund Fitzmaurice, Tia Watkins and loannis Nakas. This paper is part of the proceedings of that conference and have been edited by the organisers, with the support of Papers from the Institute of Archaeology. 
Wilkinson et al 2016). The FAIR principles and guidelines aim at targeting the production of quality data that allow for sharing and facilitating stewardship. The need for these guidelines arose from the exponential increase of complex digital data across different fields of research. Within the Humanities, the FAIR guidelines have revealed new research frontiers regarding data retrieval, management, and sharing, not only within the academic community but also among a broader audience. The need to describe and manage big and complex data in an efficient and standardized way encouraged researchers and institutions (GLAM sector - Galleries, Libraries, Archives, Museums) to use and develop descriptive systems based on the FAIR principles and guidelines, in line with EU recommendations (ALLEA report 2020).

These needs also emerged within the GRAFMEDIA research project for the documentation, cataloguing and analysis of Medieval and Early Modern graffiti in the eastern Mediterranean, along the sea route between Venice and Jerusalem. ${ }^{1}$ The project's choice to follow the FAIR principles and to apply them to the data description and structuring brought forward the methodological gaps that still affect the study of Medieval and Early Modern European graffiti. This paper presents the discussion that emerged during the initial phase of data structuring according to the FAIR principles. This article first presents a general description of graffiti material, highlighting the challenges presented by its analysis. Two selected analytical approaches are discussed to show how scholars have tried to overcome the issue concerning the graffiti graphic form. The second half of the article focuses on the graffiti constitutive elements: form, content and space. The description and discussion of the three components form the theoretical starting point of a specific methodology for European Medieval and Early Modern graffiti analysis. Moreover, the second half defines the semantic relations between these three elements. This operation is necessary and represents the first methodological step for the future creation of graffiti FAIR data, through the elaboration of additional descriptive tools, such as a specific ontology.

\footnotetext{
${ }^{1}$ GRAFMEDIA: GRAFfiti-MEDiterranean DIAlogue - Visual and verbal communication in the Medieval and Early Modern Adriatic and Eastern Mediterranean - is a MSCA project funded by the European Regional Development Fund and the Republic of Cyprus through the Research and Innovation Foundation (Project: POSTDOC/0916/0010). The project aims to document, catalogue, and study Medieval and Early Modern graffiti on selected sites along the sea routes between Venice and Jerusalem. The project's output is twofold: on the one hand, it will develop a specific methodology based on ontological description and standards combined with the creation of digital tools for the documentation and visualization of graffiti and their context. On the other hand, it investigates the Medieval and Early Modern mobility in the Eastern Mediterranean by focusing on graffiti, providing new and original data concerning the cultural exchanges through informal writings.
} 


\section{Background}

In the last two decades interest in graffiti has increased dramatically. The spread of contemporary graffiti and the development of their study have altered the way graffiti are viewed by scholars, tracing their historical roots to Prehistory. This trend is confirmed by recent conferences and publications on the topic, which provide a diachronic perspective and emphasize the relevance of context in attempts to comprehend the production and the evolution of graffiti over time (Keegan 2014: 16ff.; Lovata et al 2015; Ragazzoli et al 2018; Lohmann 2018, 2020; Sarti 2020; Fleming 2020). Moreover, the advancement of graffiti studies has established the significance of this peculiar written source in offering a valuable insight into past societies through a privileged point of view: the voices of ordinary people in their everyday life. Due to the ease of graffiti production, everyone can potentially leave a mark on any available surface, with no formal restrictions. The absence of standards and rules — unlike many forms of writing - establishes graffiti as a free, spontaneous way of expression, with heterogeneous forms merged in an attempt to leave a mark behind and communicate a message. Though spontaneity may be seen as a valuable and beneficial feature of graffiti, there are significant challenges with regard to the intention behind the vast variety of graffiti forms, inscriptions and drawings.

However, the increase of interest and research in the field did not go hand in hand with the development of a specific analytical methodology. While palaeography and epigraphy can provide a robust methodology for the study of textual graffiti, art history and anthropology offer additional methodological tools to analyse drawings, marks and symbols. These different approaches to the subject have produced helpful results in using original data for the study of various aspects of past societies which are not recorded in traditional written sources. Nevertheless, numerous challenges arise in the analysis of such heterogeneous material. De facto graffiti studies have borrowed their methodologies from other disciplines, without attempting to develop their own. However, standards specific to the study of graffiti has hindered the development of this field at large. The absence of shared, objective analytical standards leaves space for subjectivity based on researchers' interests and expertise. Moreover, the production of non-standardized data prevents their sharing and exchange, obstructing the comparison of data between different contexts and, therefore, the progress of research. 
To address the challenges mentioned above, the GRAFMEDIA project employed the FAIR data policy and developed a semantic description system for graffiti studies. To achieve this goal, it was necessary to start by considering the different experiences of researchers working in different contexts. Two approaches (discussed below) seem to be particularly efficient in offering elements for the development of a specific Medieval and Early Modern graffiti analytical frame. The first result was the identification of three constitutive elements of graffiti: form, context, and space. As the study of graffiti is still in its infancy, this paper aims to raise questions and encourage methodological debate on Medieval and Early Modern graffiti rather than providing answers or setting guidelines.

\section{Different Analysis Approaches}

Writing Before Writing: Rock. Art and Its Analytical Approach Through a Case Study Current narratives regarding graffiti consider it to be an enduring phenomenon that dates back to Prehistory. In such an extended period, graffiti have adapted and changed their form and function according to numerous variables, such as social and historical circumstances. Beyond these variations, in a broader and general perspective, graffiti continue to be expressed in a dimension of timeless space. In this perspective, significant historical events, such as the invention of writing systems, seem not to have affected the universal features of the phenomenon. The invention of writing systems is rightly considered a turning point, an event which has profoundly modified several aspects of life, yet, according to scholars, not the practice of graffiti (Lovata et al 2015; Ragazzoli et al 2018). What has actually altered with regard to graffiti since the introduction of writing systems is the methodological approach to their analysis. The study of Pre-Historic and Historic graffiti could benefit greatly if methodological approaches considered the relevant writing systems associated with the graffiti in question.

Some of the earliest forms of graffiti (e.g., Chauvet cave, 36.000-32.000 BP) are referred to as Rock Art in the form of petroglyphs or pictographs due to the context in which they were created and executed. The study of petroglyphs and pictographs portraying concepts, ideas, and narratives offers a valuable insight into prehistoric societies that goes beyond material evidence (Keegan 2014: 17-21). As a subfield of archaeology, the study of rock art has evolved significantly since its inception in the 1980s, largely due to research in the Val Camonica region. This area of the Italian 
Alps hosted one of the first extensive and structured studies of rock art. The presence of numerous rock carvings had already been known since the beginning of the 20th century. Even before WWII, several archaeologists had reported on the wide variety and abundance of rock art evidence, dating back to the 8th millennium BC and extending up to the end of the Middle Ages.

In the 1950s Emmanuel Anati started a systematic study on prehistoric evidence, documenting and cataloguing the rock art in Val Camonica, applying a holistic methodology which allowed the integration of the landscape as a constitutive element of the analysis. One of the significant outcomes of his study was the creation of typologies based on the forms present within the rock art which, combined with the data distribution and context, allowed him to identify the chronological evolution of the motifs. Anati's work led to the recognition of the area as the first Italian UNESCO site (1979). In 1964, the Centro Camuno di Studi Preistorici was founded, aiming to document, study, and preserve rock art in the Val Camonica area but with potential to include international rock art cases. Anati had an innovative approach to the subject and was able to establish a robust methodological foundation based on archaeological traditions, integrated with art history and anthropology. His methodology outlines every phase of the research process thoroughly, from surface preparation, to documentation, cataloguing, study and final interpretation. The innovative aspect of his work led to the creation of formal typologies, exclusively based on the visual aspect of the carvings. By integrating the description of rock art forms with distribution and context, Anati provided a valid base for the interpretation of rock art evolution, meaning, and function in the prehistoric society of Val Camonica (Anati 1976). A step forward was achieved through the testing of this methodology in other contexts with positive results. The systematically documented forms resulted in a formalised typology which also suited other regions outside of Val Camonia, enabling the comparison among various sites and areas under common and shared standards.

The result was the creation of Rock Art development models, which can be applied to prehistoric societies all over the world (Anati 1994, 2002). With his work, Anati demonstrated that Rock Art-graffiti could be used as a primary source for the study of different aspects of society, such as sociocultural developments and economic status. A step forward was made by the creation of digital tools and systems for the 
documentation, cataloguing and monitoring of the area by researchers of the Italian Ministry of Cultural Heritage and Activities, in collaboration with an international network of experts who managed different sites all over the world. Thanks to this experience, rock art can now benefit from a robust methodology, guidelines and good practice concerning the documentation, study and preservation of rock carvings (Ruggiero et al 2009: 1-3; Ruggiero 2015: 2321-2325), including the use of innovative digital applications for visualization and data management (Baker 2018).

Combining Texts and Images: Analytical Approaches to Medieval and Early Modern European Graffiti

The second methodological approach considers graffiti from historic periods, in which the material includes not only figures and motifs but also texts recording the language. After the creation of writing systems, and more specifically of alphabets (by Phoenicians in the 15th century BC), the attention of scholars studying European graffiti started focusing on texts. Thanks to disciplines such as palaeography and epigraphy, the text may be deciphered and the writing characteristics may be analysed to extract not only the content but also other relevant information about the time, and in some cases even the author and the context. The word 'graffiti' was used for the first time in mid-19th century, after the discovery of the sites of Herculaneum and Pompei, to describe the scratched inscriptions recovered on the walls of the cities' buildings (Garrucci 1856; Champion 2018: 626-627; Lohmann 2020: 40). During the discovery of the two Roman cities, archaeologists noticed and started studying the informal inscriptions scratched or painted on the walls of houses and public buildings. In these two contexts, graffiti mainly constituted of alphabetical inscriptions, hence they were initially included in the field of epigraphy. Since then, graffiti discoveries were documented in epigraphic Corpora, based on chronology, language and area, such as the Inscriptiones Graecae (IG) and the Corpus Inscriptionum Latinarum (CIL) for the classical period (Lohman 2020: 43-44), and Corpus des Inscriptions de la France Médiévale (CIFM), Deutsche Inschriften (DI) and Inscriptiones Maedii Aevii Italiae (IMAI) for the Middle Ages. The epigraphic standards for cataloguing have been developed with great consideration for the material and immaterial aspects of the inscriptions (Panciera 2012; Grossi 2016). These standards are constantly evolving thanks to the application of digital tools and digital data management that provide holistic documentation of the epigraphic record (Felicetti et al. 2015, 2017; Lamè et al.: 2015). In this context, graffiti are described and catalogued following the 
Classical and Medieval epigraphic standards. However, it should be stressed that in the ongoing debate on the definition of 'inscription', graffiti are often brought up as problematic due to their pictural nature and general lack of epigraphic data (Panciera 2012: 4, 9; Felle 2017: 599ff.). For instance, the discussion often revolves around publicity as a common feature of the inscriptions; graffiti are displayed in public places aiming at conveying a message to audience as wide as possible. Yet this aspect is not always valid for graffiti, which Antonio Felle (2017: 602) describes as the most private form of exposed writings and the most public form of private ones ('la forma più privata delle scritture esposte e la forma più pubblica delle scritture private').

Within these corpora, graffiti appear ephemeral and of minor relevance due to the unavoidable comparison with the rest of the inscriptions. Graffiti are less articulated, more challenging to read, sometimes merely depicting a single word, such as a name. However, if we observe the same graffiti from an individualistic perspective, as a separate entity from epigraphic inscriptions, the perception of the graffiti changes. When every single graffito is relocated in its context, and only then, does it manage to transmit all its value as a written source, an operation that fails when placed within epigraphic collections. The context, as emphasized in the last decades, constitutes an essential element for the study and understanding of graffiti (Keegan 2014; Baird et al 2011). The context includes material aspects such as the position in the space of the inscriptions and the description of its support. Other less physical considerations should also be taken into account: what is the function of the structure or context in which the graffiti is found? The function of a site may alter our interpretation of the graffiti. Furthermore, the function of a site may change over time, or it may not always be consistently used by the same communities.

Although context is an essential element for the study of inscriptions too, the descriptive standards that are currently available in the field of epigraphy are insufficient to describe graffiti adequately. Nevertheless, the primary limitation of using epigraphic standards for the study of graffiti is the unfeasibility of carrying out an inclusive analysis that can also embrace non-textual material, which for the Middle Ages, for example, represent the most consistent part.

In the epigraphic panorama, graffiti represent an exception which, on a methodological level translates into a challenge: the creation of a specific analytical 
and descriptive system suitable for both forms (texts and drawings) without favouring one over the other. The first step in this direction was made in the UK for the Medieval and Early Modern periods. Graffiti attracted attention at the end of the $19^{\text {th }}$ century, but it was only after the beginning of the $20^{\text {th }}$ century that scholars started focusing on the subject more vigorously (Champion 2017: $19 \mathrm{ff}, 34-35)$. Reference works are the contributions of G.G Coulton (1915), and R. Hine (1951: 206-215) who were able to understand the global relevance of graffiti as a written historical source, although their interest was text-oriented. Their beneficial contribution was a shift to a more anthropological approach to the phenomenon. Even Reginald Hine, rigidly text-oriented, emphasized the peculiarity of graffiti in recoding messages, feelings, rituals of people who marked the church walls with their signs, integrating the material evidence of graffiti with the interest in the individuals who produced them. A step forward was made by Violet Pritchard (1967) with her pioneering work English Medieval Graffiti (Champion 2015: 3-5). In the volume, she published selected graffiti from churches 'mostly within a radius of sixty miles of Cambridge' (Pritchard 1967: xi), including a few examples of graffiti from her surveys in England, Scotland and Wales to show the wide spread of the phenomenon and to foster the interest and research in this field (Pritchard 1967: 173). It is possibly the first time that texts and drawings were studied with equal interest and attention. Hence, the common text-oriented approach was gradually overturned.

The drawings are in some ways of greater interest than the inscriptions, for they invoke the past in a manner which no inscription could achieve. A picture arrests time and brings to life a lost moment in a century long past.' (Pritchard 1967: xii)

This inclusive and large-scale approach has marked the new path in the field, even if it took a few decades to implement Pritchard's experience widely. The first attempts were developed in Germany by Detlev Kraack (1997) and Martin Langner (2001). Kraack performed a large-scale survey in Italy and the Eastern Mediterranean mapping and collecting graffiti left by nobles during their pilgrimage to the Holy Land $\left(14^{\text {th }}-16^{\text {th }}\right.$ century). Despite the focus on a selected group of graffiti, the author collected both, textual and pictorial graffiti - personal names/signatures and coats of arms - left by nobles. The innovative aspect of this work lies in the fact that, for the first time, graffiti of a different form - textual and pictorial - have been considered 
as an expression of the same message: to mark the presence - in this case of a nobleman - in a shrine. A few years later, Martin Langner (2001) bridged the lack of attention to non-textual graffiti in antiquity. In his work, he presented nearly 2500 graffiti from 683 sites showing the relevance of this written form to the more wellknown textual graffiti from sites such as Pompeii. He classified the material based on their thematic and visual form, describing their distribution and context. Langner contributed greatly to raising awareness on the different forms of graffiti, showing that pictorial graffiti are as widespread as textual ones, as well as equally relevant for a universal analysis. Despite the relevance of his work, the author's aim was not to create a single system for cataloguing all the material, but rather to show the relevance and variety of pictorial graffiti within a period for which only textual graffiti had been considered.

The real recovery of Violet Pritchard's holistic approach took place in 2010 in England, with the creation of the Norfolk Medieval Graffiti Survey (NMGS) thanks to the foresight of Matthew Champion. ${ }^{2}$ Starting from the material collected by Pritchard, Champion decided to undertake a systematic and accurate campaign for the documentation of the graffiti still preserved on the numerous parish churches of the county. Helped by the availability of new methods and tools for documentation, such as digital photography and its numerous applications, as well as with the collaboration of trained and organized volunteers, the NMGS collected thousands of graffiti from almost all parish churches of the county. As a consequence, the successful project obtained numerous official awards for its innovative approach, not only in the field of graffiti studies but also for promoting a new approach to community archaeology and for raising awareness on the value and relevance of graffiti within the general public. After the successful experience of NMGS, other counties saw the creation of archaeologist led groups of volunteers aiming to follow the Norfolk example. ${ }^{3}$ From a methodological point of view, with NMGS project, Matthew Champion developed the first inclusive list of graffiti types, where textual and pictorial graffiti are listed together. Thanks to the director's archaeological approach, NMGS offered the first guidelines for the documentation and preliminary cataloguing of graffiti, based on a structured reference scheme. Matthew Champion's main contribution is the shaping of a methodology focusing on graffiti as written

\footnotetext{
2 http://www.medieval-graffiti.co.uk/index.html

3 http://www.medieval-graffiti.co.uk/page106.html
} 
evidence tout-court, without excluding any form. The strong link between graffiti, their support and context has been objectively defined for the first time through the documentation sheets created for NMGS fieldwork. Moreover, for the first time the graffiti types are listed and grouped under standardized names, in contrast to the general practice of researchers to use various names (i.e. pelta/Gordian knot/Solomon's knot; hexfoil/rosette/compass drawn design), expanding the reference vocabulary rather than focusing on creating a shared one.

NMGS represents a promising starting point to further develop a shared and robust methodology, inclusive of all graffiti forms, focusing on the description rather than the interpretation. Champion's archaeological approach has marked a path towards the inclusive and objective description of graffiti that leads the way to a solid foundation for graffiti studies. The significant number of documented sites and graffiti allowed him to perform large-scale analysis and interpretation, based on objective, reliable and comparable data on which the articulated and accurate interpretation of his work Medieval graffiti (2015) is based. Nevertheless, some considerations must be expressed regarding the cataloguing system developed within NMGS project. The first concerns the organization of graffiti types which are grouped under mixed formal and interpretive categories (i.e. 1. Apotropaic; 12. Animals - Fig 1). Although the assignments are correct for the British context, their accuracy is not yet certain for other contexts, especially outside Great Britain. Furthermore, on a methodological level, classification should aim at objectivity, without including interpretative elements in the field of description. This method is necessary to ensure that interpretations which may be applicable in specific areas will not automatically be applied to contexts for which they may not be valid. For Instance, a form such as the pelta which in England is given apotropaic value (Fig 1; Champion 2015: 56-58) does not carry the same function in other areas like Italy or the Eastern Mediterranean (Trentin 2011: 191.). A second observation is that the listed types include only the most common forms. All other graffiti types can be documented and reported in the designated 'photo record sheet'. However, it should always be taken into consideration that all NMGS guidelines and graffiti types have been developed and are applicable on surveys and fieldwork where the primary purpose is to provide graffiti documentation, to identify their distribution and to plan their conservation and valorisation. 


\section{MEDIEVAL GRAFFITI TYPES}

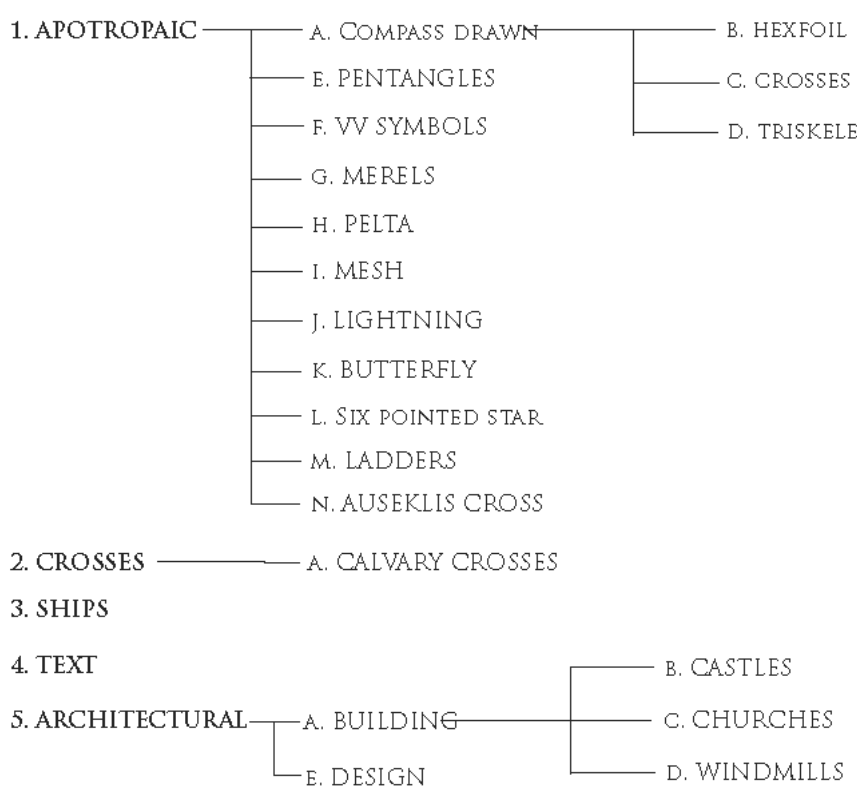

6. MERCHANTS MARKS

\section{MASONS MARKS}

8. MASS DIALS (SCRATCH DLALS)

9. MUSICAL A. INSTRUMENTS

- B. NOTATION

10. HERALDIC A. SHIELD

11. FIGURES A. FUll Length figure

B. FACES

C. DEMONS

D. GROTESQUES

12. ANLMALS A. HORSE

B. DEER

C. DOG

D. BIRD

13. RAGGED STAFF

14. HANDS

15. SHOES/FEET

16. GAMING BOARDS

17. WEAPONS/TOOLS

18. PLANTS

19. DOT PATTERNS

20. OTHER

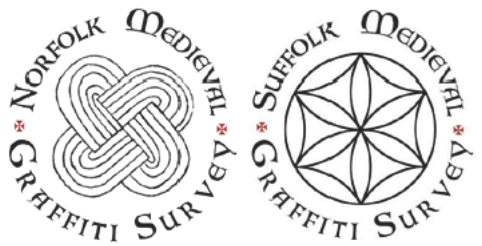

Figure 1: NMGS, Medieval graffiti types by Matthew Champion. 
A contribution of great significance with regard to Matthew Champion's approach is the introduction of formal types. So far, although the nature and meaning of the various forms of graffiti have been recognized and explained, the definition of typologies has not been based on formal elements. Even today, the commonly used categories to define graffiti are based on their function (apotropaic, commemorative, devotional, ludic, etc.), content (erotic, political, religious etc.) or location (urban graffiti, prison graffiti, bathroom-latrinalia, etc.) (Sarti 2020: 11). As in the case of pelta, scholars are aware that the same form can assume different meaning and function depending on the context. Therefore, if the focus shifts to function rather than form, the comparison between different sites and areas will be challenged and compromised, being based on subjective (interpretation) rather than objective (form) elements.

This exposition of the current approaches on the study of graffiti shows both the potentials and limitations still present for the definition of an inclusive and specific graffiti methodology. Rock Art and epigraphy are undoubtedly efficient in describing and analysing pictorial and textual graffiti respectively. Moreover, applying objective descriptors, such as form and location, the two systems may collect data which can be compared within different contexts, fostering scientific exchange and promoting a broader understanding of Rock Art and epigraphs. For graffiti, a first positive attempt was made by NMGS application of guidelines and typologies on documentation and cataloguing. Furthermore, NMGS achieved to overcome the division between pictorial and textual graffiti creating a solid foundation for future development. Following the author's expertise (mentioned above), the following sections will deal with Medieval and Early Modern graffiti, even if the general approach may be extended to other periods.

\section{Graffiti Constitutive Elements: Form, Content, Space}

Despite various attempts, researchers have not been able to formulate a complete and satisfactory definition for graffiti so far. In the last decade many steps were made towards the enhancement of knowledge and analysis of the phenomenon, which contributed to the identification of its bounteous facets, common features and anomalies (Fleming 2020). Nevertheless, this advancement is still inadequate. The following section will endeavour to follow a different path: to describe rather than define. The ultimate aim is not to achieve definition, but a theoretical description that 
uses the materiality of the graffiti as a starting point and attempts to define the communication and creation processes that led to its realization. It follows a bottomup approach, starting from the materiality of graffiti as an artefact and reaching a theoretical description of the three fundamental characteristics and their reciprocal links. It represents an ontological approach to graffiti. This dissertation has been the starting point for the creation of a specific ontology for graffiti, which is currently being finalized ${ }^{4}$.

The developments described in the first part indicate how the current fragmented methodology may be overcome through objective reflection and description - as it was done in Rock Art and Epigraphy - and how subjective elements such as interpretation should be avoided in the first phase of description. The theoretical approach presented below fits into this path and aims to foster the discussion on the development of a unifying methodology for graffiti by researchers, which will bring different perspectives together. Graffiti literature in the last decade identified two main elements, form and context, emphasizing that only through their combination can the meaning and function of graffiti be acquired (Baird et al. 2011, Lovata et al 2015: section 1, 2; Dirven et al 2018: 5ff.). Yet, a third element should be added to these two, the content.

\section{Form}

As discussed above, the main obstacle that arises in the study of graffiti is the presence of heterogeneous forms deriving from the expressive freedom offered by graffiti. People making graffiti are not obliged to follow graphic rules that favour text to drawing. Consequently, an inclusive analysis system is imperative so as to describe and consider the two written expressions on the same level. From a formal point of view, graffiti can be divided into textual and pictorial, with a further distinction in the latter category between figurative and geometrical. Figurative graffiti represent, to different degree of detail, real things such as human figures, animals, objects and monuments, while geometrical graffiti consist of single or combined geometric elements. Alphabetical writing is recognized globally, yet it requires more considerable effort in the deciphering process. Text writing firstly requires the

\footnotetext{
${ }^{4}$ A CIDOC CRM graffiti ontology has been developed with the collaboration of Achille Felicetti at PIN in Prato within the Transnational Access Programme of ARIADNEplus (https://ariadne-infrastructure.eu), supported by the European Commission Horizon 2020 Programme under Grant Agreement number: 823914 - ARIADNEplus H2020-INFRAIA-2018-2020/H2020-INFRAIA-2018-1.
} 
organization and codification of thought in linguistic form. Then, once articulated, the language must be codified and written down through a series of signs - the letters of the alphabet. On the other end of the communication process, a reverse procedure is applied by the reader, though reading a text does not necessarily lead to its comprehension. The alphabetical codification does not transmit a content automatically, since letters and their combination are a set of conventional and abstract signs established by an arbitrary agreement (Cardona 1981: 48; Trentin 2011: 147). A paradox is that one may read Italian well enough thanks to its straightforward pronunciation, but if he does not know the language, the communication process does not work, and the message is not delivered. This constitutes both a strength and a limitation of the alphabetical system.

Pictorial graffiti, which include figurative and geometrical graffiti, codify thought in a different way. Figurative graffiti correspond to pictograms (Anati 1994: 39; Trentin 2011: 162). Pictography delivers content without the interference of language to the message. The more limited the linguistic or conceptual value associated with the pictogram, the more efficient the communication mechanism will be, reaching an ideal case of perfect matching between pictogram and word. By depicting real objects and things, pictography manages to transmit the content as the human mind recognizes it, in the shape of the corresponding real object. The mental transition is almost immediate, given that it happens within a circumscribed context in which the terms are known to all (Cardona 1981: 40). In this case, pictography constitutes the most effective system, able to express the graphic transposition of contents known to all, as well as their logical concatenations, even if unexpressed (Cardona 1981: 40). This undoubtedly constitutes a significant advantage in the use of this system (Cardona 1981: 40-41). The last group consists of geometric graffiti (Trentin 2011: 183). The definition derives from the choice to distinguish the material in a graphic and non-content-cognitive point of view. On a graphic level, all the forms of this group are characterized by geometric elements and represent stylizations of real elements, symbols, simple geometric figures or compositions. Geometric graffiti correspond to ideograms, abstract figures that express abstract and more articulated concepts than pictograms. Ideograms are the basis of universal logographic writings, which can be read in various languages, and which correspond to unique signs, or sets of signs, to a concept, an idea or a message, rather than to a particular word. Thanks to their immediacy and universality, logographic writings are widespread 
today, for instance in the form of road signs and emoticons used in our daily personal communication. Ideograms can be 'read' without requiring linguistic processing, and this is their communicative strength: they are international. As highlighted before, the communicative efficiency of ideograms is based on the shared and explicit knowledge of the components and their mutual connection within a group, overcoming language barriers. Hence, the form reflects a precise communicative mechanism that can only be reconstructed through the objective analysis of the form.

Based on what has been described above, there has been an apparent shift of perspective. Though alphabetical writing had always been considered as the privileged form of communication, within the context of graffiti it appears to be the least versatile. Scratching or tracing a text on a hard surface not intended for writing may require considerable effort. In order to express an abstract concept, one would need to carve more than one line of text, tracing legible letters to deliver a message. Despite all this effort, it is not certain whether the potential reader will be able to read and understand the written language. Pictorial graffiti, on the other hand, prove to be more effective for communication. In fact, drawing offers more freedom in the expression of thoughts, not being restricted by linguistic conventions. Pictorial graffiti carry a shared meaning, and their communication efficiency lies on their identification and diffusion.

In light of these last considerations, the common conclusion that the absence or minimal presence of alphabetic writing in graffiti is an indication of low literacy is refuted. The conscious selection of a communication code, and whether the use of alphabets serves the writer's purpose, is not always dictated by the writer's ability or graphic knowledge, but rather by the message he wants to communicate. As graffiti writing is performed on rigid surfaces, without predefined or established rules, its form is often defined by the conciseness and effectiveness of communication. These two characteristics are often best achieved by non-alphabetic graphic forms, as manifested in our daily experience. Moreover, the use of images in graffiti indicates a more articulated communication system based on the perception of texts and images, often linked to particular mnemonic mechanisms (Carruthers 2002: 29; Fleming 2001: 44). In this context, texts and images may be chosen at the moment of writing depending on their communicative effectiveness. This graffiti mechanism has been illustrated in the English context by Juliet Fleming (2001: 29) and Matthew 
Champion (2012; 2015: 85ff.; 111ff.), showing how texts and images were integrated in the minds and perceptions of Medieval and Early Modern societies.

\section{Content}

The second element under consideration with regard to graffiti is content. Unlike form and space, content is a more abstract but essential concept. The relationship between form and content can be traced thanks to semiotics, thus identifying the ontological aspects of graffiti. Graffiti content does not correspond to the function but expresses the meaning(s) that can be associated with a form. The function is the result of a combined interpretation of the form, the content and the location (space).

Considering content as a vital element of graffiti helps us understand the structure and formation process of graffiti at a communicative level, enabling a more objective description. In semiotic terms, when we see a graffito scratched or traced on a wall, we are looking at a sign, an entity composed of one or more elements on the level of expression (signifier-form) and one or more elements on the level of content (meaning-content) (Eco 2016: 77). Hence, form and content create the sign-graffito. It is important to underline that the relationship is not univocal, i.e., a form can correspond to multiple contents and vice versa (Eco 2016: 77). Moving the discussion on a practical level, let us consider the example of a ship graffito (formsignifier). In terms of content (meaning), the drawing can be associated with multiple solutions, all ascribable to the same ship graffito which can indicate the means of transport for a traveller, the workplace for a sailor, a votive offering for a worshipper, a landscape element for a coastal inhabitant. Thus, various contents may correspond to a single form. By reversing the perspective, a single content can be expressed by different forms. A Medieval nobleman who wanted to create a graffito in order to represent and identify himself could choose among at least three solutions: to write his name, draw his coat of arms or draw his self-portrait, as Detlev Kraack illustrated in his work (1997).

These theoretical considerations are essential not only from a strictly ontological point of view but also from a practical one, as they contribute to describing the communication mechanism that is implemented through graffiti. The multiple correspondences between form and content (signifier and signification) allow to keep in mind all the different possibilities of reading and associating the two concepts. 
Therefore, the rigid and univocal association of one form to one concept should be prevented. Returning to what was said above about the form, heterogeneity, i.e., the presence of forms belonging to different graphic systems (textual and pictorial), shows the peculiarity of graffiti compared to traditional written sources. Since there are no codes to follow, every signifier-meaning association is possible in both directions. Moreover, the even more relevant aspect underlined by Umberto Eco concerns the referent, which represents the ideal social concept conveyed by the signifier through the meaning. The three elements -signifier, meaning and referentare linked through the semiotic triangle (Fig 2) (Ogden et al 1923: 11; Eco 2016: 92). The criticism of Eco's concept of referent will not be further analysed, what is relevant for the present discussion is the affirmation that an expression does not designate an object but conveys a cultural content (Eco 2016: 95). Here, Eco emphasizes that a given sign is closely linked to the society that produces it, merging form and content, and creating a sign according to the cultural features of that specific society. This is also true for pictograms and ideograms. Thus, for other coeval societies or in the same society but in different eras, the referent - object of the expression - may not be understood in the same way. More simply, bringing attention back to our topic, the expression conveyed by a graffito is the result of the cultural content of the society that produced it, and the more culturally or temporally distant the society that reads it, the more difficult it is to comprehend it.

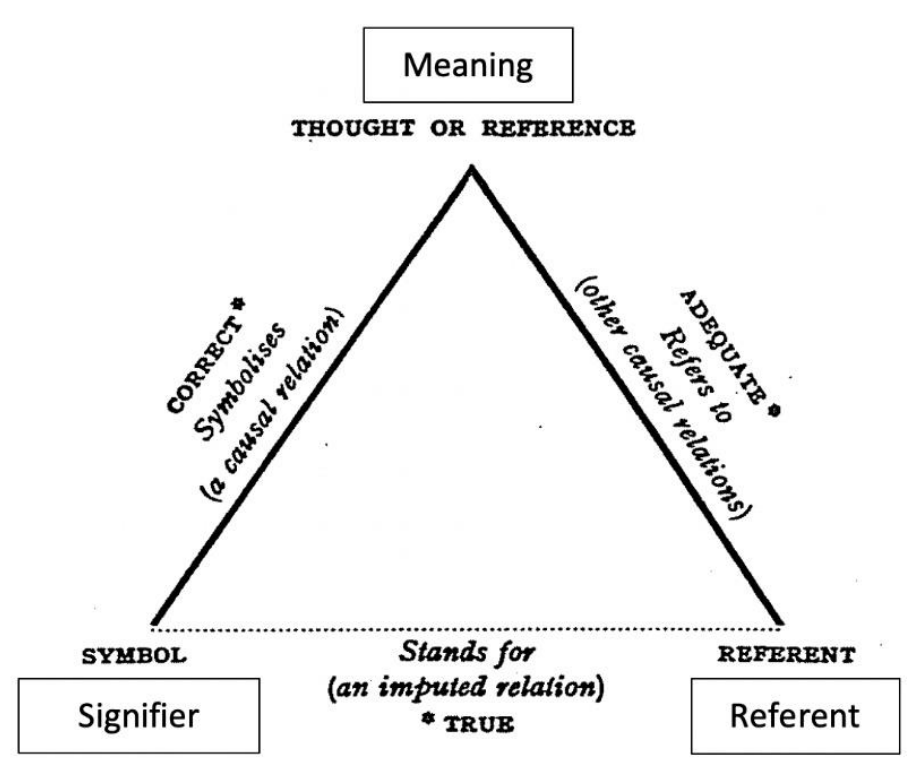

Figure 2: The Semiotic triangle (Odgen and Richards, 1923) 
This aspect is already evident in graffiti studies, and scholars are aware that the only way to 'read', understand and interpret graffiti is through a multidisciplinary approach, since it is necessary to recover the cultural aspects of the society that produced them. The awareness concerning how articulated the process of expression is - as well as awareness on the difficulty of reading and understanding sources of the past - leads us to admit that sometimes it may not be possible to understand the content at all. This is the case of some graffiti forms such as what Matthew Champion named lightning, butterfly and ladder in his graffiti types form (http://www.medieval-graffiti.co.uk/graffiti\%20types4.pdf). Even if their content is difficult to be recovered today, the documentation and analysis of these forms are necessary to be performed in an inclusive study. Before the NMGS experience, these forms were often overlooked, and their distribution and frequency were unknown. Thanks to the comprehensive and punctual documentation of NMGS, these forms have become visible, constituting an essential reference for other contexts such as the Italian (Trentin 2011: 198; 649) and Cypriot (Trentin 2018; Trentin 2021) ones. It is likely that one day, thanks to the comparison between different sites and contexts, these forms will be more understandable. Though their specific content may not be defined, we will have a better understanding on how and where they were used, enhancing and refining our knowledge about graffiti as a whole. The content of graffiti is usually taken into account for the analysis of textual graffiti, following the methodology applied to texts. However, as seen above, in a comprehensive study of graffiti, content must be considered on a broader level and also extended to pictorial graffiti. The impossibility of reconstructing an explicit content, as it can be done in the case of texts, must not discourage the analysis of all the forms that can be observed and documented. These forms, that in a semiotic sense are signs, are 'content carriers'. And although the reconstruction of the message - or cultural content as defined by Eco - is more complicated or sometimes impossible, the task is merely to document it in any case. This allows a more detailed knowledge of all the graffiti material and offers the possibility to obtain useful data for the specific site through other approaches such as the distributive analysis, and to perform fruitful comparisons with other areas, as demonstrated by the work of NMGS.

Space

After form and content, space is the third constitutive element for the study of graffiti. Scholars have extensively underlined the relevance of context for the analysis 
and interpretation of graffiti (Baird et al 2011; Lovata et al 2015; Dirven et al 2018: $11 \mathrm{ff}$.). From this point of view, graffiti appears chameleonic; the same form in different context acquires different meaning and performs a different function. A name scratched in a brothel wall in Pompei does not carry the same meaning as a name scratched in a church wall, possibly close to relics or the main altar.

The concept of context, though, involves objective and interpretative elements. It includes the physical position of graffiti within the structure or environment, as well as the information regarding the function, meaning and value of place or space, retraced through a process of historical reconstruction from its origins until today. The discussion on context is never objective since it involves, even at a small extend, the interpretation of that space, of its social and cultural value both in its original and current form. Context is what makes people consider graffiti as vandalism tout court. Today it is known that this practice was largely accepted in Medieval and Early Modern Europe (Plesch 2010), and the shift in attitude can be detected in the $19^{\text {th }}$ century (Champion 2017; Ritsema van Eck 2018). The main reason for this change in behaviour was the emergence of the concept of cultural heritage. From this perspective, monuments and sites are first seen as something to preserve and protect, and sometimes this perception is applied retrospectively, creating a misunderstanding. A practical example of an objective approach in this sense is provided by epigraphy. When an inscription is damaged, the so-called damnatio memoriae appears on the list of possible causes of damage. This expression formally describes an act of vandalism, the deliberate damage made on an artefact to delete its content, either entirely or partially (Di Stefano Manzella 1987: 60). This is an accepted practice not only within its original context but also today, with scholars documenting this act as the will to cancel and destroy an artefact or part of it deliberately. However, this act is never associated with the modern concept of vandalism because it is considered in an objective perspective (Flower 2006; Lori Sanfilippo et al 2010). The damnatio memoriae testifies a historical intervention that adds information concerning the reception and audience reaction to the artefact (Plesch 2002: 140). Graffiti also constitute an interaction between man and the surrounding space which must be documented objectively, without judgment or interpretation.

There is always a high risk to consider space through current perspectives, even involuntarily, thus enabling modern superstructures to affect the objectivity of the 
observation and analysis. Thinking in terms of context creates a non-objective method of description, attributing to space features that must be considered in a final step, the interpretation process. Graffiti do not have to fit into the context; they contribute to its definition. For these reasons, the concept of space, rather than context, is more suitable for an objective approach. Space is considered as a way to specify or measure the graffiti position on a wall or a surface, a building or an area. Recording the position of graffiti in space is also fundamental so as to perform accurate distributive analysis from a micro to a macro scale, supporting the final interpretation and the general understanding of the phenomenon. Moreover, as underlined by Matthew Champion (2018: 618), the graffiti distribution within sites allows us to have a more objective picture of the possible selection that graffiti have undergone over the centuries due to changes in the support and/or building on which they are found. This problem is particularly relevant in the United Kingdom where Reformation profoundly modified the original aspects and even the structure of religious buildings. Space provides a more reliable and objective category to describe graffiti, while a more articulated concept of context should be included in the following phase of interpretation.

\section{Conclusions}

In this paper I propose a theoretical discussion on the methodological aspects related to the description and analysis of European Medieval and Early Modern graffiti, based on the developments of the last decade in the graffiti field of study. So far, different contributions have tried to shape a general definition often coming to admit that this is an impossible challenge due to the innumerable facets and variations that this unitary but heterogeneous and long-lasting phenomenon presents (Fleming 2020). Through the implementation of FAIR data concept for graffiti, this paper offers a different approach, aiming to describe rather than define. The first part presents existing methodologies employed to graffiti cataloguing. These are sometimes specific, such as the Rock Art and NMGS, or developed for the analysis of artefacts -inscriptions - in which graffiti can be included even partially (only texts). The first two examples present structured methodologies which are able to describe and analyse Rock Art and inscriptions, offering a solid foundation to the final step of research, i.e., interpretation. The two systems, however, do not allow to carry out an analysis on all the forms of European Medieval and Early Modern graffiti, composed by textual and pictorial material that must be considered and described by 
a single system. NMGS has already addressed this limitation by proposing a structure capable of describing both forms, offering an initial step for the further development of a specific methodology. The system proposed by NMGS, although effective, has some limitations due to the documentation function that it had to fulfil. It presents a mixed formal-functional system that limits the objectivity of the description and inserts the interpretation in the initial phase. The first part, therefore, wants to illustrate how methodologies based on the objective description of the material in all components offer a solid basis for the next phase of analysis and interpretation. Furthermore, the description using formal and objective typologies guarantees the possibility of applying a methodology in different contexts allowing a uniform exchange of data between researchers and contributing to the development of knowledge of the phenomena observed on a larger scale. This is precisely what FAIR data principles and guidelines promote in the field of Humanities as well. The second part is devoted to the identification and theoretical description of the elements that characterize graffiti, as a first step towards the development of a structured methodology. Through the theoretical description of the fundamental characteristics of graffiti - form, content and space - an attempt is made to explain the mechanisms that carry communication within graffiti. This theoretical step is necessary so as to proceed with the definition of a specific ontology, a conceptual reference model that identifies and binds together all the characteristics and elements that constitute graffiti with semantic relationships. These elements are fundamental in the creation of a specific system of description, as in the cases of Rock Art and epigraphy.

A drawback of graffiti studies is the absence of a holistic object description based on standards that describe the material in all its aspects, keeping into account all the elements mentioned above. The lack of standards and of a structured description is currently undermining progress in this field. The absence of a specific, shared model able to catalogue graffiti limits the holistic analysis considerably and, consequently, the data exchange among researchers around the world. The takeaway of this paper encourages scholarly discussion that will finally lead to the creation of a specific methodology for the study of European Medieval and Early Modern graffiti, recognizing the uniqueness of this source within the broader panorama of written sources. 
Acknowledgements: The author would like to thank Achille Felicetti (PIN-Prato), Francesca Murano (UNIFI) and Valentina Vassallo (CyI) for the fruitful discussions and suggestions on graffiti theoretical and ontological aspects. The work and support of the Timeless Space Symposium organizers Rosamund Fitzmaurice, Tia Watkins and Ioannis Nakas were greatly appreciated. The author wishes to extend her special thanks to Matthew Champion for granting the permission of using the NMGS graffiti typology tab (fig. 1) and to the anonymous reviewers for their valuable comments and suggestions.

\section{REFERENCES}

ALLEA report 2020 Sustainable and FAIR data sharing in the Humanities [online] February 2020. Available at:

https://www.ria.ie/sites/default/files/allea sustainable and fair data shari ng in the humanities 2020 0.pdf [Last accessed 9 July 2021].

Anati, E 1976 Metodi di Rilevamento e di Analisi dell'Arte Rupestre. Studi Camuni 7. Capo di Ponte.

Anati, E 1994 Arte Rupestre: Il Linguaggio Primordiale. Studi Camuni 12. Capo di Ponte.

Anati, E 2002 La Struttura Elementare dell'Arte. Studi Camuni XXII. Capo di Ponte.

Baird, J and Taylor, C (eds.) 2011 Ancient Graffiti in Context. London: Routledge.

Baker, F 2018 Pitoti Prometheus, virtual reality 360: Valcamonica rock art between naturalism and alienation, in Di Giuseppantonio Di Franco, P et al Authenticity and Cultural Heritage in the Age of 3D Digital Reproductions. Cambridge: McDonald Institute for Archaeological Research. pp. 123-34.

Cardona, G R 1981 Antropologia della scrittura. Torino: Loescher.

Carruthers, M 2002 Le Livre de la Mémoire. La Mémoire dans la Culture Médiévale. Paris: Macula Éditions. [1990. The Book of Memory. A Study of Memory in Medieval Culture. Cambridge: Cambridge University Press]

Champion, M 2012 The medium is the message: votive devotional imagery and gift giving amongst the commonality in the late Medieval parish. Peregrinations: 
Journal of Medieval Art \& Architecture 3(4): 103-23. Available at:

https://digital.kenyon.edu/perejournal/vol3/iss4/3/ [Last accessed 9 July 2021].

Champion, M 2015 Medieval Graffiti. The lost voices of England's churches. London: Ebury press.

Champion, M 2017 The Priest, the Prostitute, and the Slander on the Walls: Shifting Perceptions Towards Historic Graffiti. Peregrinations: Journal of Medieval Art and Architecture 6(1): 5-37. Available at:

http://digital.kenyon.edu/perejournal/vol6/iss1/20 [Last accessed 9 July 2021].

Champion, M 2018 Medieval Graffiti Inscriptions, in Gerrard C and Gutiérrez A (eds.) The Oxford Handbook of Late Medieval Archaeology. Oxford: Oxford University Press, 626-40.

Coulton G G 1915 Medieval Graffiti. Proceedings of the Cambridge Antiquarian Society XIX: 53-62.

Di Stefano Manzella, I 1987 Mestiere di Epigrafista. Guida alla Schedatura del Materi ale Epigrafico Lapideo. Roma.

Driven, L and Van Gelder, M 2018 Inleiding. Graffiti van de oudheid tot heden, in Tijdschrift voor Geschiedenis 131(1): 1-15. DOI:

https://doi.org/10.5117/TVGESCH2018.1.DIRV

Eco, U 2016 [1976] Trattato di Semiotica Generale. Milano: La Nave di Teseo.

Felicetti, A, Murano, F, Ronzino, P, and Niccolucci, F (2015) CIDOC CRM and Epigraphy: A Hermeneutic Challenge, in Ronzino, P and Niccolucci, F (eds.) Extending, Mapping and Focusing the CIDOC CRM, CRMEX, Poznán, Poland, $55-68$

Felle, E 2017 Casi di epigrafi 'non esposte': alcune considerazioni. Studi Medievali s. III, LVIII.II: 579-606.

Fleming, J 2001 Graffiti and the Writing Arts of Early Modern England. London: Reaktion Books.

Fleming, J 2020 Graffiti Futures. Journal of Early Modern Studies 9: 29-36.

Flower, H I 2006 The Art of Forgetting: Disgrace and Oblivion in Roman Political Culture. University of North Carolina Press. 


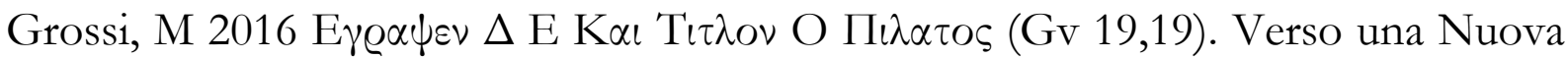
Definizione di Iscrizione. Zeitschrift für Papyrologie und Epigraphik 197: 85-95.

Garrucci, R 1856 Graffiti de Pompéi. Inscriptions et gravures. Paris: Benjamin Duprat.

Hine, R 1951 Church Graffiti, in Relics of an Un-Common Attorney. London: Dent. 20615.

Keegan, P 2014 Graffiti in Antiquity. London: Routledge.

Kraack, D 1997 Monumentale Zeugnisse der spätmittelalterlichen Adelsreise. Inschriften und Graffiti des 14.-16 Jabrhunderts. Göttingen: Vandenhoeck und Ruprecht.

Lamé, M Sarrullo, G et al 2015 Technology \& Tradition: A Synergic Approach to Deciphering, Analyzing and Annotating Epigraphic Writings. Lexis 33: 9-30.

Langner, M 2001 Antike Graffitizeichnungen. Motive, Gestaltung und Bedeutung. Palilia 11. Wiesbaden: Reichert Verlag.

Lohmann, P (ed.) 2018 Historische Graffiti als Quellen: Methoden und Perspektiven eines jungen Forschungbereichs. Stuttgard: Franz Steiner Verlag.

Lohmann, P 2020 Historical Graffiti: The State-of-the-Art. Journal of Early Modern Studies 9: 37-56.

Lovata, T R and Olton, E (eds.) 2015 Understanding Graffiti: Multidisciplinary Studies from Prebistory to the Present. London: Routledge.

Ogden, C K and Richards, I A 1923 The Meaning of Meaning: A Study of the Influence of Language upon Thought and of the Science of Symbolism. London: Kegan Paul, Trench, Trubner \& co LTD.

Panciera, S 2012 What Is an Inscription? Problems of Definition and Identity of an Historical Source. Zeitschrift für Papyrologie und Epigraphik 183: 1-10.

Plesch, V 2002 Graffiti and Ritualization: San Sebastiano at Arborio, in Rollo-Koster, J (ed.) Medieval and Early Modern Rituals: Formalized Behavior in Europe, China and Japan. Leiden, 127-46.

Plesch, V 2010 Destruction or Preservation? The Meaning of Graffiti at Religious Sites, in Raguin, V (ed) Art, Piety and Destruction in European Religion, 1500-1700. Aldershot: Ashgate, 137-72.

Pritchard, V 1967 English Medieval Graffiti. Cambridge: Cambridge University Press. 
Ragazzoli, C, Harmanşah, Ö, Salvador, C and Frood, E (eds.) 2018 Scribbling through History: Graffiti, Places and People from Antiquity to Modernity. London: Bloomsbury Academic.

Ritsema van Eck, M 2018 Graffiti in Medieval and Early Modern Religious Spaces: Illicit or Accepted Practice? The Case of the Sacro Monte at Varallo. Tijdschrift voor Geschiedenis 131(1): 51-72. DOI:

https://doi.org/10.5117/TVGESCH2018.1.RITS

Ruggiero, M G 2015 Monitoring and best practices for the tutelage of the rock art heritage of Valle Camonica UNESCO Site, in The World Heritage List, ARKEOS 37, XIX International Rock Art Conference, IFRAO 2015, pp. $2321-5$.

Ruggiero, M G, Poggiani Keller, R, Liborio, C, Dimitriadis G and Coimbra, F 2009 Introduction, in UISPP 2006, Session WS 20 Rock. Art Data Base New methods and guidelines in archiving and cataloguing. BAR International Series 1996, 29, pp. 1-3.

Sanfilippo, I L and Rigon, A (eds.) 2010 Condannare all'oblio. Pratiche della Damnatio Memoriae nel Medioevo. Istituto Storico Italiano per il Medioevo, Roma.

Sarti, R 2020 Editorial. Journal of Early Modern Studies 9: 7-26.

Trentin, M G 2011 I graffiti come fonte per la storia delle pratiche religiose medievali. Unpublished thesis (PhD), University of Venice Ca' Foscari. Available at: http://hdl.handle.net/10579/1079 [Last accessed 9 July 2021].

Trentin, M G 2018 Geometrical Graffiti: Challenges of Interpretation and an Example from Timios Stavros in Pelendri. Second Annual Conference on Byzantine and Medieval Studies, Nicosia, 12-14 January 2018. Unpublished Conference Presentation. Available at: https://www.academia.edu/35671051/Geometrical_Graffiti_Challenges_of Interpretation and an Example from Timios Stavros in Pelendri [Last accessed 9 July 2021].

Trentin, M G In Press Medieval and Early Modern Graffiti: multicultural and multimodal communication in Cyprus. Cahier du Centre d'Etudes Chypriotes 50.

Wilkinson, M, Dumontier, M, Aalbersberg, I et al. 2016 The FAIR Guiding Principles for scientific data management and stewardship. Sci Data 3(160018). Available at: https://doi.org/10.1038/sdata.2016.18 [Last accessed 9 July 2021]. 